\title{
Accuracy Assessment of the Network Real-Time Kinematic Techniques for Geodetic and Plane Coordinates
}

\author{
Bakar, N.A.M.A. ${ }^{1}$, Din, A.H.M. ${ }^{1,{ }^{*}}{ }^{2}$ Zulkifli, N.A. ${ }^{1}$, Amat, M.A.C. ${ }^{3}$ and Hamden, M.H. ${ }^{1}$ \\ ${ }^{1}$ Geospatial Imaging and Information Research Group (GI2RG), Faculty of Built Environment and Surveying, Universiti \\ Teknologi Malaysia, 81310 Johor Bahru, Johor, Malaysia \\ ${ }^{2}$ Geoscience and Digital Earth Centre (INSTeG), Faculty of Built Environment and Surveying, Universiti Teknologi \\ Malaysia, 81310 Johor Bahru, Johor, Malaysia \\ ${ }^{3}$ Geodetic Survey Division, Department of Survey and Mapping Malaysia (DSMM), Jalan Sultan Yahya Petra, 50578
}

Kuala Lumpur, Wilayah Persekutuan Kuala Lumpur, Malaysia

\begin{abstract}
Virtual Reference Station (VRS), Master-Auxiliary Corrections (MAX) and Individualised MasterAuxiliary Corrections (IMAX) are among the Network Real-Time Kinematic (NRTK) techniques supported by Malaysia Real-Time Kinematic GNSS Network (MyRTKnet) in rendering networkbased solution to users. However, different network corrections have different limitations due to different manufacturers hence offering varieties output. Therefore, this study was conducted to assess the accuracy of VRS, MAX and IMAX for geodetic and plane coordinates. Three (3) techniques were implemented to observe points at Universiti Teknologi Malaysia (UTM) and cadastral lot in Johor Bahru. The results were analysed based on assessment with known values and baseline lengths. The findings showed that the accuracy of all techniques ranged from 0.16 to $3.61 \mathrm{~cm}$ (horizontal) and 2.86 to $6.20 \mathrm{~cm}$ (vertical) for geodetic coordinates. For plane coordinates, the values varied from 0.3 to $4.22 \mathrm{~cm}$ (horizontal) and 2.1 to $8.26 \mathrm{~cm}$ (vertical). IMAX provided the worst accuracy compared to others due to incompatibility of Radio Technical Commission for Maritime Services (RTCM) format. Moreover, the accuracy decreases as the baseline length between rover and reference station increases. In conclusion, VRS and MAX yielded acceptable accuracy and can be safely chosen rather than IMAX. Furthermore, the baseline length for applications involving high accuracy measurement should also be considered.
\end{abstract}

Keywords: Network RTK techniques; MyRTKnet; VRS; MAX; IMAX

\section{INTRODUCTION}

Accurate and precise measurements are of utmost important to many surveying and mapping applications. Network RealTime Kinematic (NRTK), one of the most commonly used techniques for various applications was introduced in mid1990 (Wubbena et. al., 2001; Wanninger, 2008; Kim \& Bae, 2015). This method was applied in practices through the approaches of Virtual Reference Station (VRS), Flachen Korrektur Parameter (FKP) and Master-Auxiliary Concept (MAC) with the aim to provide an immediate and well accurate positioning information around the clock (Ogutcu \& Kalayci, 2016; Park, 2008; Takac \& Zelzer, 2008; Janssen, 2009) while reducing an investment cost required to start a Real-Time Kinematic (RTK) positioning service (Wanninger, 2008). The NRTK technique along with the approaches of VRS, FKP and MAC have been widely implemented in countries such as Japan, Korea, China, Turkey and Europe by utilising existing communication services covering their respective regions (Wanninger, 2008; Bae \& Kim, 2018; Chan \& Ben, 2007; Cina et. al., 2015; Gumus \& Selbesoglu, 
2019). In Malaysia, Department of Survey and Mapping Malaysia (DSMM) has developed Malaysia Real-Time Kinematic GNSS Network (MyRTKnet) since 2004 to facilitate fast and accurate surveys by introducing the NRTK technique, which models the spatial and temporal errors that affect Global Navigation Satellite Systems (GNSS) signals. MyRTKnet offers several NRTK services including two (2) of the most commonly used services which are VRS and MAC with its Master-Auxiliary Corrections (MAX) and Individualised Master-Auxiliary Corrections (IMAX) approaches.

The central concept of NRTK is to improve the long-range ambiguity resolution by generating reliable error models that can mitigate dispersive (ionosphere related) and nondispersive (troposphere-related and orbit related) signals components. Ambiguity resolution is an analytical procedure to determine the integer cycle of the GPS phase observations (Shariff et al., 2009). Due to the aforementioned fact, ambiguity resolution is essential, in which failure or incorrect resolution could lead to the degradation of the quality of solution (Lim et al., 2020). It is for this reason that NRTK has been accepted widely as a capable technique in providing highly accurate coordinate from GNSS measurement.

This NRTK technique is made up by permanent GNSS receivers' network that continuously transmit observation of the satellite to a central server. The concept of networkbased positioning involves three (3) basic processes: i) data processing from master to reference station, ii) network corrections generation and iii) data processing on user side. In order to support NRTK users, all computation must be performed as fast as possible. Figure 1 illustrates the concept of NRTK positioning.

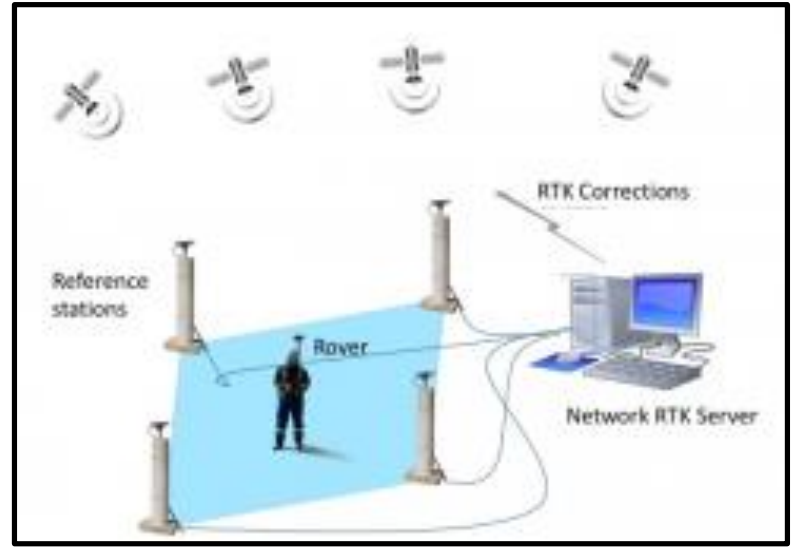

Figure 1. The concept of NRTK positioning (Canadian Geodetic reference System Committee, 2020)

\section{A. Virtual Reference Station (VRS)}

The concept of VRS which has been proven and broadly employed is an approach of generating GNSS reference stations data for an imaginary reference station, located near to the initial rover position (refer Figure 2). It is a combination approach of modelling the network and representing the network corrections for users. The VRS approach necessitates at least three (3) reference stations linked to a network server, which requires two-way communication (Inal et al., 2018).

VRS allows the complex modelling of atmospheric effect in the server by taking into account the full network information (Janssen, 2009). In other words, no complex computations are involved at the rover. However, there are constraints to the kinematic application, specifically when rovers pass across wide areas with one dial-in time. If the rover travels further from the initial VRS, a new VRS needs to be decided.

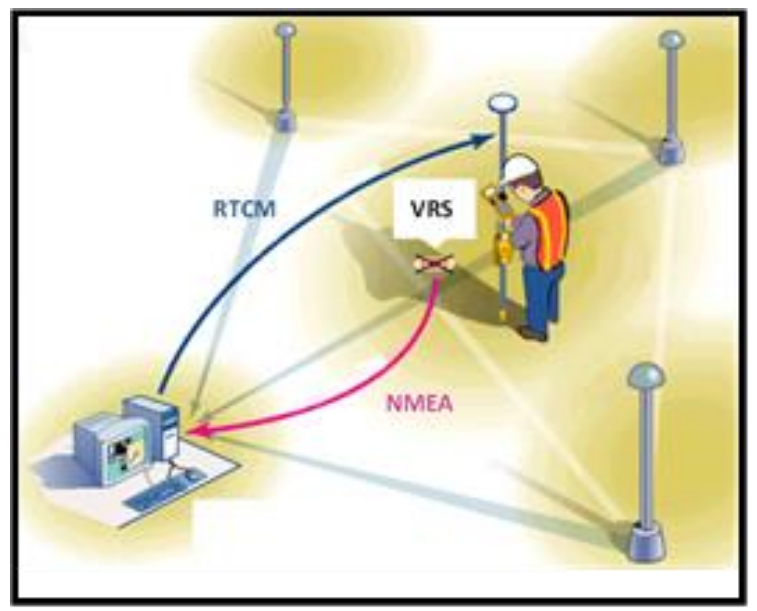

Figure 2. The principle of VRS (Landau et al., 2002) 


\section{B. Master Auxiliary Correction (MAX)}

The transmission of MAX is utilised based on the MAC principle (Euler et al., 2001) as well as depending on a tiered system of networks, cluster and cell (Janssen, 2009). In contrast to VRS, this concept can be either two-way or oneway communication, as illustrated in Figure 3. Therefore, it is important to note that for two-way communication, the process occurs automatically through the receiver transmitting its approximate position; otherwise, the master station is predetermined by the user manually. The interpolation of this network correction is achieved using the full information of the network by the rover that supports Radio Technical Commission for Maritime Services (RTCM) 3.1 network messages.

The complete information about the prevailing sources of error is made accessible to the rover through RTCM; permitting more intelligent positioning algorithms to be used at the rover to determine the position (Janssen, 2009). According to Janssen (2009), if there are no network corrections obtainable (e.g., due to insufficient pairs between satellite and receiver with fixed ambiguity), then correction will not be transferred and user must adapt a single-based solution.

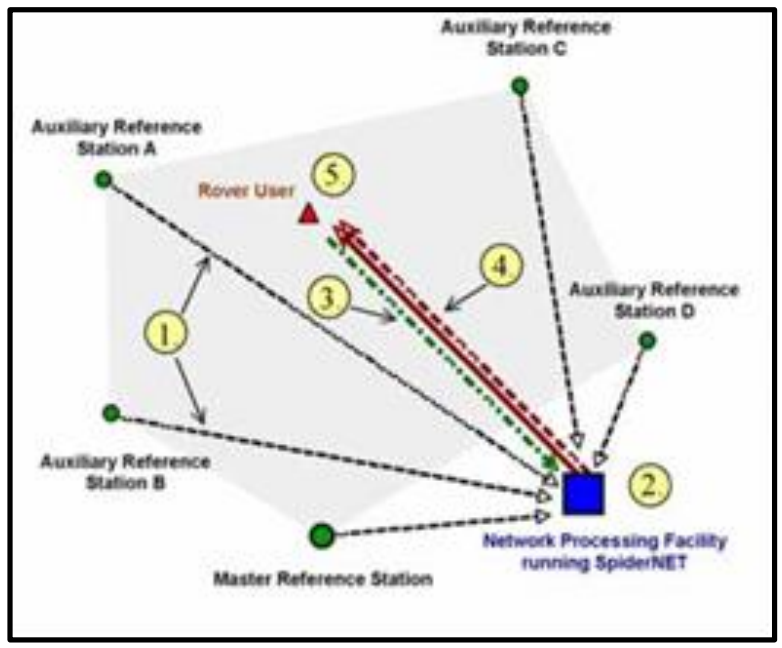

Figure 3. The MAX principle (Brown et al., 2005)

\section{Individualised Master-Auxiliary Correction (IMAX)}

IMAX was developed at the same time as MAX to support older receivers that cannot interpret the RTCM 3.1 network messages. The IMAX and VRS techniques are similar; both are classified as individualised corrections involving the rover to send its approximate position to the server. The important processes in the uses of IMAX are equivalent to MAX, with the exemption that the network server will calculate and implement network corrections for the rover to the master station. Contradict to VRS, for each rover, IMAX provides individual RTK corrections based on a real reference station.

Every rover must generate its approximate position for the system to identify the closest reference station (Jensen, 2017), meaning that two-way communication must be established either by telephone or over the internet (Garrido et al., 2011). The concept of IMAX approach is demonstrated in Figure 4.

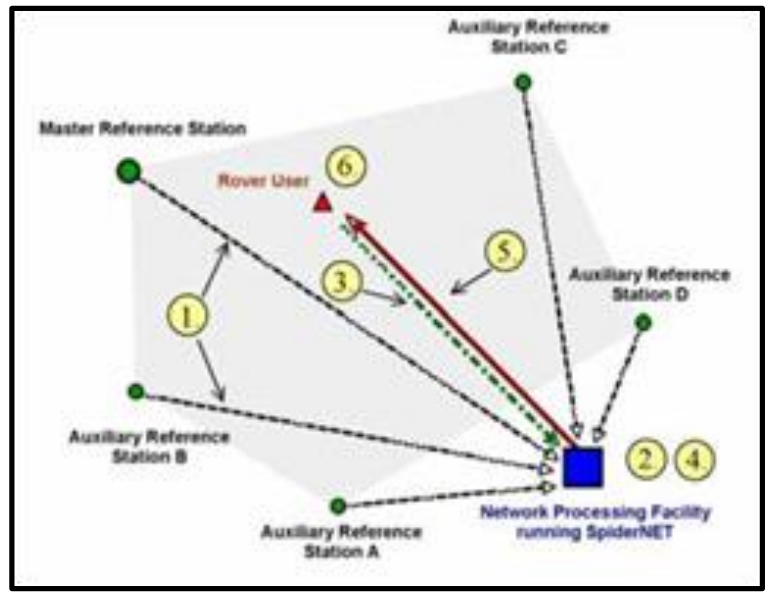

Figure 4. The IMAX principle (Brown et al., 2005)

Therefore, this study presents an effort to assess the accuracy of NRTK techniques for geodetic and plane coordinates, focussing only on the approaches of VRS, MAX and IMAX as implemented by DSMM. In order to realise the aim, a few points at Universiti Teknologi Malaysia (UTM) and nearby cadastral lot in Johor Bahru have been observed. Comparisons of the results were divided into two (2) cases of geodetic and plane coordinates: i) with known values and ii) between baseline lengths. In addition, this study intends to highlight NRTK techniques by comparing their significance and accuracy that could be beneficial to MyRTKnet users by identifying the best technique that provides the highest precision in positioning (geodetic coordinates) and mapping (plane coordinates) as well as maintaining the accuracy as required. However, it should be noted that each of the NRTK techniques is unique in their principles, with different concepts and implementations that could result in different outcomes and accuracies. Each of the characteristics of VRS, MAX and IMAX are summarised in Table 1. 
Table 1. Summary of the characteristics of VRS, MAX and IMAX techniques (Janssen, 2009; Cina et. al., 2015; Berber \& Arslan, 2013)

\begin{tabular}{|c|c|c|}
\hline VRS & MAX & IMAX \\
\hline 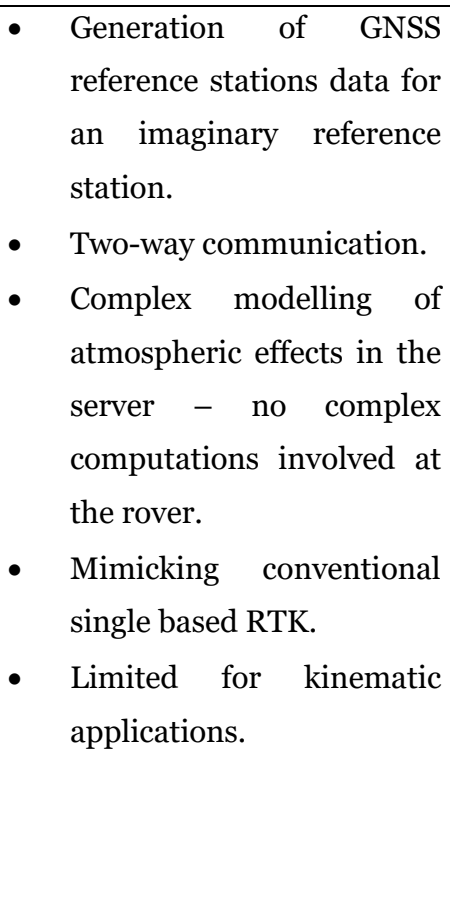 & 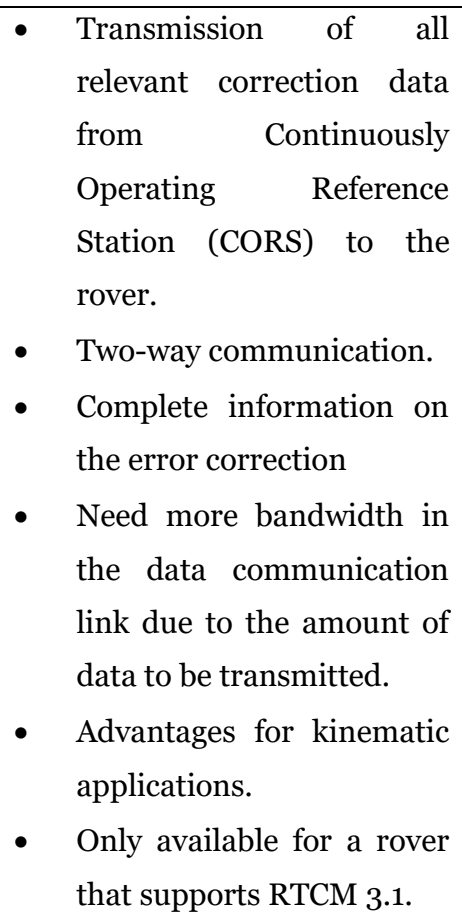 & 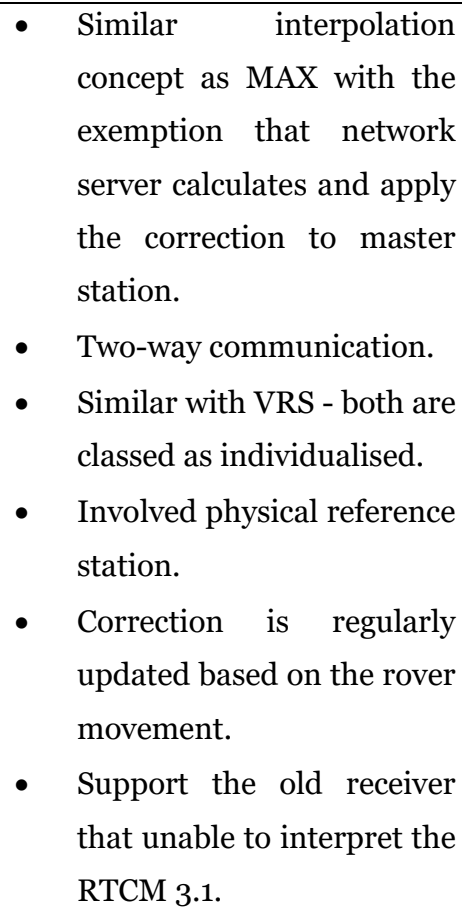 \\
\hline
\end{tabular}

\section{DATA AND METHODS}

From this study, there are two (2) main purposes conducted and analysed based on different points and areas which are i) geodetic (positioning) and ii) plane (mapping) coordinates. For positioning purpose, the area of interest was at UTM, whereas for mapping purpose, the study was carried out at Kg. Melayu, Johor Bahru, Johor. Figure 5 shows the locations of three (3) arbitrary chosen geodetic markers among the points established in UTM meanwhile, Figure 6 shows three (3) Cadastral Reference Mark (CRM) points with known coordinates within the same cadastral lot located at Kg. Melayu, Johor Bahru. Both areas were chosen due to the accessibility of the location. Besides, any information on cadastral lot (for mapping) can be easily obtained from the Land Office (LO) within the region.

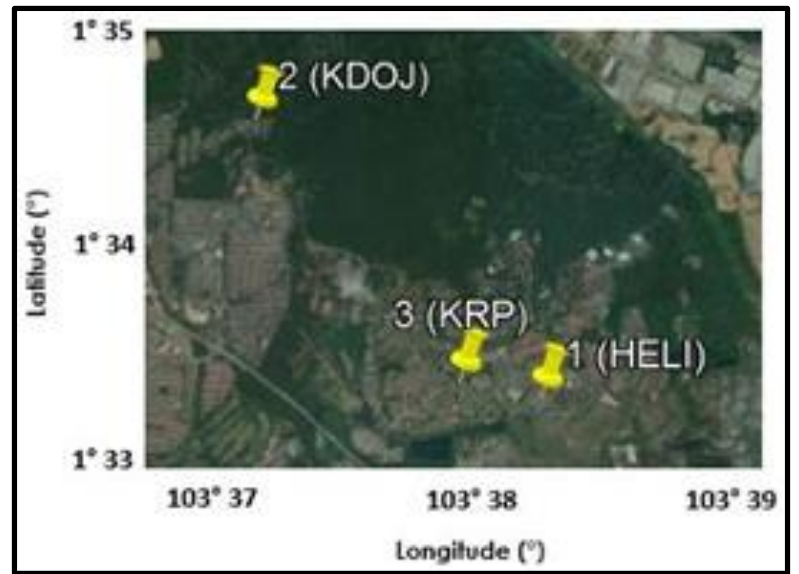

Figure 5. Location of the geodetic markers at UTM for positioning (source: Google Earth)

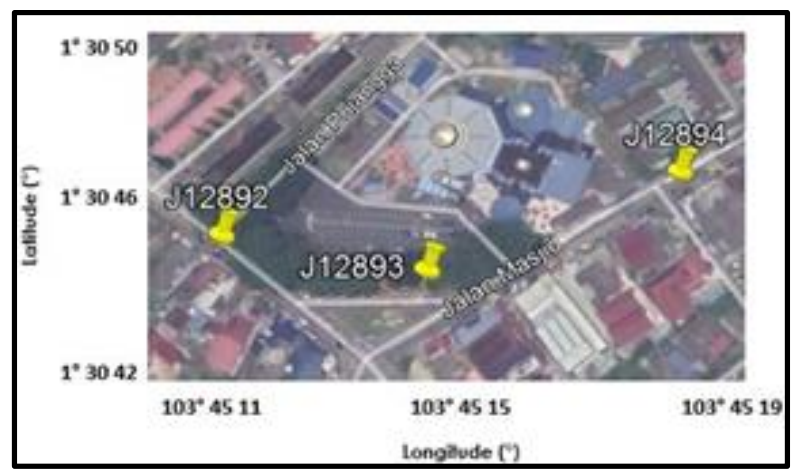

Figure 6. Location of the CRM points at Kg. Melayu, Johor Bahru, Johor for mapping (source: Google Earth) 
In this section, VRS, MAX and IMAX methods are assessed based on two (2) classifications, namely i) comparison with known values and ii) between baseline lengths. The main idea of these assessments is to evaluate the accuracy of the observation points' position according to the NRTK techniques involved.

\section{A. Comparison of Geodetic Coordinates with Known Values (Positioning)}

Each result from the NRTK techniques at the observed points is compared to the true coordinate obtained from static GNSS observation. This comparison allows the reliability assessment of each NRTK techniques. From the comparisons, the accuracy (represented by Root Mean Square Error (RMSE)), precision (represented by standard deviation), magnitude and direction were calculated and tabulated. The formulas involved in deriving the RMSE, standard deviation, magnitude and direction are shown per Equations (1) to (4) below (Howell 1998; Ghilani, 2010):

$$
R M S E=\sqrt{\frac{\sum_{i=1}^{n}\left(p_{i}-a_{i}\right)^{2}}{n}}
$$

where,

$p_{i}$ : coordinates from each network correction technique

$a_{i}$ : coordinates from static GNSS observation or CRM

$n$ : number of observation

$$
\sigma=\sqrt{\frac{\sum_{\mathrm{i}=1}^{\mathrm{n}}(\mathrm{xi}-\mu)^{2}}{\mathrm{~N}-1}}
$$

where,

$\sigma:$ sigma/standard deviation

$\mathrm{N}$ : size of data

xi : each data values

$\mu:$ mean of data

$$
\begin{gathered}
\text { Magnitude }\left(D_{A B}\right)=\left[\left(E_{B}-E_{A}\right)^{2}+\left(N_{B}-N_{A}\right)^{2}\right]^{1 / 2} \\
\text { Direction } \emptyset_{A B}=\tan ^{-1}\left\lfloor\frac{E_{B}-E_{A}}{\left(N_{B}-N_{A}\right.}\right\rfloor
\end{gathered}
$$

where,

A and B : two (2) different techniques

$\mathrm{E}$ and $\mathrm{N}$ : coordinates of observed points

\section{B. Comparison of Plane Coordinates with Known Values (Mapping)}

CRM is a monument that is often used as control or datum for the cadastral survey. In Malaysia, the cadastre system is managed by two (2) main agencies, namely DSMM and LO. Both of these agencies are responsible for the cadastral spatial information and the cadastre attribute information, respectively (Hassan et al., 2008). Therefore, the observations for this section took place on the three (3) CRM points located at Kg. Melayu, Johor Bahru, Johor. The location of the three (3) CRM points at Kg. Melayu, Johor Bahru, Johor is illustrated in Figure 6. The same formulas (1) to (4) were used to compute the values of RMSE, standard deviation, magnitude and direction between the observed and known coordinates.

\section{Baseline Lengths}

In general, NRTK technique is made up by permanent GNSS receivers' network that continuously transmits observation of the satellite to a central server, combines the data and produces corrections within the area covered by the reference stations while interpolating those corrections to the rover position (Ogutcu \& Kalayci, 2017). The software on the server will automatically choose the closest MyRTKnet station to the rover. The master station is always selected as the closest to the rover, while auxiliary stations are chosen from the surrounding stations (Janssen, 2009).

In this case, the accuracy of NRTK was accessed by taking into account the baseline lengths between the nearest MyRTKnet station and the rover. Therefore, JHJY station was chosen as it was the closest station located to the points of interest. JHJY station served as a guide in classifying points for short and long baseline lengths. For the short baseline, the observed point is located at $\mathrm{Kg}$. Melayu, Johor whereas for long baseline, the point is located at UTM. Figure 7 displays the location of the observed points according to baseline lengths. 


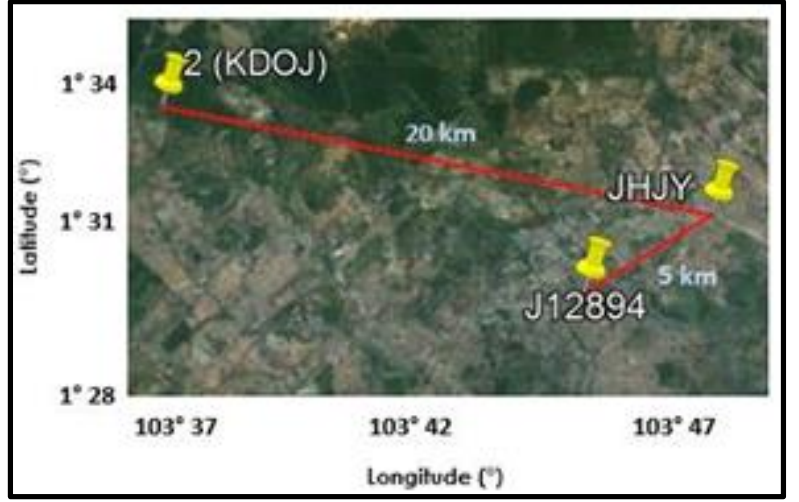

Figure 7. Location of observed points for the evaluation of baseline lengths (source: Google Earth)

\section{Data Acquisition and Processing}

In order to acquire the known coordinate of the observed points in geodetic coordinate, a static GNSS observation of 8-hours was conducted using Topcon GR-5 dual-frequency receiver on $12^{\text {th }}$ February 2019. The GNSS data was processed using Trimble Business Centre (TBC) postprocessing software that can compute coordinate solution accurately within few centimetres level (Soko, 2018). The three-dimensional $(3 \mathrm{D})$ control networks were tied to three (3) MyRTKnet stations, namely JHJY, KUKP and SPGR.
For the plane coordinate, coordinates of the CRM points were downloaded from the DSMM website known as JUPEM2U Johor. These coordinates were treated as the ground truth value for the assessment of coordinates from the NRTK techniques. Both true coordinates of points located in UTM (latitude, longitude, ellipsoidal height (h)) and CRM points (northing $(\mathrm{N})$, easting (E), ellipsoidal height (h)) are tabulated in Table 2.

Then, the NRTK techniques were observed at the same 8hours observation points ( $25^{\text {th }}$ March 2019) and CRM points (19 ${ }^{\text {th }}$ March 2019) using Topcon HiPer HR using three (3) different MyRTKnet services which were VRS, MAX and IMAX. For each observation, five fixed solution epochs were collected concurrently with a 1-second sampling rate, and the average of these five (5) epochs was recorded as a single measurement. In total, twenty-five (25) measurements were obtained for each technique from five (5) different initialisations. The mean coordinate from the NRTK techniques was then compared to the known values obtained from static observation. Table 3 summarises the processing parameters and strategies implemented in the TBC postprocessing software followed by Figure 8, illustrating the data collection at UTM and Kg. Melayu, Johor, Johor Bahru.

Table 2. True values for geodetic and plane coordinates

\begin{tabular}{|c|c|c|c|}
\hline \multicolumn{4}{|c|}{ Geodetic Coordinates } \\
\hline Points & Latitude & Longitude & $\mathbf{h}(\mathbf{m})$ \\
\hline 1 (HELI) & $1^{\circ} 33^{\prime} 29.60131^{\prime \prime}$ & $103^{\circ} 38^{\prime} 13.35441^{\prime \prime}$ & 42.0900 \\
\hline 2 (KDOJ) & $1^{\circ} 34^{\prime} 34.50924 "$ & $103^{\circ} 37^{\prime} 12.39913 "$ & 52.2720 \\
\hline 3 (KRP) & $1^{\circ} 33^{\prime} 33.64825 "$ & $103^{\circ} 37^{\prime} 56.67691^{\prime \prime}$ & 33.2620 \\
\hline \multicolumn{4}{|c|}{ Plane Coordinates } \\
\hline CRM Points & $\mathbf{N}(\mathbf{m})$ & $\mathbf{E}(\mathbf{m})$ & $\mathbf{h}(\mathbf{m})$ \\
\hline J12892 & -58600.7340 & 21364.7480 & 28.9660 \\
\hline J12893 & -58620.3720 & 21465.8040 & 33.8080 \\
\hline J12894 & -58571.4740 & 21589.8360 & 30.9200 \\
\hline
\end{tabular}

Table 3. Processing strategy for post-processed using TBC

\begin{tabular}{cc}
\hline Processing Parameters & Processing Strategies \\
\hline Elevation mask & $10^{\circ}$ \\
Processing interval & $10 \mathrm{~s}$ \\
Orbit/clock & Broadcast \\
Type of solution & Fixed \\
\hline
\end{tabular}



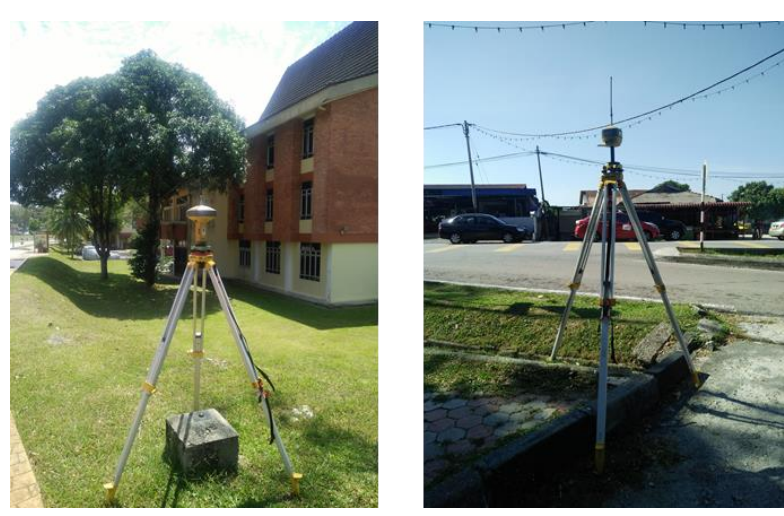

Figure 8. GPS data collection at UTM (left figure) and Kg.

Melayu, Johor Bahru, Johor (right figure) using Topcon GR-

5 dual-frequency receiver and Topcon HiPer HR, respectively.

\section{RESULTS AND DISCUSSION}

The interpretation, analysis and discussions are presented in this section. Results and discussion comprise of all research methodology from geodetic to plane coordinates. Analyses were made in terms of the achievable RMSE (accuracy), standard deviation (precision), magnitude and direction of output from each NRTK technique.

\section{A. Comparison of Geodetic Coordinates with Known Values (Positioning)}

The comparisons between the true coordinates and the coordinates obtained from the NRTK techniques of each observed point along with their standard deviations were calculated and tabulated in Table 4. Following that, the result from those comparisons was used to compute the RMSE for northing, easting and ellipsoidal height (h) (refer Table 5). The magnitude and direction of output from each NRTK technique are presented in Tables 6 to 8 .

Table 4. Mean coordinates and standard deviation of NRTK techniques

\begin{tabular}{|c|c|c|c|c|}
\hline \multirow{2}{*}{ Points } & \multirow{2}{*}{ NRTK } & \multicolumn{3}{|c|}{ Mean Coordinates } \\
\hline & & Latitude & Longitude & h (m) \\
\hline \multirow{3}{*}{1 (HELI) } & VRS & $1^{\circ} 33^{\prime} 29.60221^{\prime \prime}$ & $103^{\circ} 38^{\prime} 13.35429 "$ & 41.9860 \\
\hline & MAX & $1^{\circ} 33$ ' 29.60254" & $103^{\circ} 38^{\prime} 13.35429 "$ & 42.0078 \\
\hline & IMAX & $1^{\circ} 33^{\prime} 29.60234 "$ & $103^{\circ} 38^{\prime} 13.35500 "$ & 41.9515 \\
\hline \multirow{3}{*}{2 (KDOJ) } & VRS & $1^{\circ} 34^{\prime} 34.51060 "$ & $103^{\circ} 37^{\prime} 12.39889^{\prime \prime}$ & 52.2080 \\
\hline & MAX & $1^{\circ} 34^{\prime} 34.51030^{\prime \prime}$ & $103^{\circ} 37^{\prime} 12.39869^{\prime \prime}$ & 52.1652 \\
\hline & IMAX & $1^{\circ} 34^{\prime} 34.50659^{\prime \prime}$ & $103^{\circ} 37^{\prime} 12.39666^{\prime \prime}$ & 52.3652 \\
\hline \multirow{3}{*}{3 (KRP) } & VRS & $1^{\circ} 33^{\prime} 33.64884^{\prime \prime}$ & $103^{\circ} 37^{\prime} 56.67727^{\prime \prime}$ & 33.1448 \\
\hline & MAX & $1^{\circ} 33$ ' 33.64839" & $103^{\circ} 37^{\prime} 56.67788^{\prime \prime}$ & 33.1284 \\
\hline & IMAX & $1^{\circ} 33^{\prime} 33.64956^{\prime \prime}$ & $103^{\circ} 37^{\prime} 56.67613 "$ & 33.1630 \\
\hline \multirow{2}{*}{ Points } & \multirow{2}{*}{ NRTK } & \multicolumn{3}{|c|}{ Standard Deviation } \\
\hline & & Latitude (cm) & Longitude (cm) & h (cm) \\
\hline \multirow{3}{*}{1 (HELI) } & VRS & 0.36 & 0.50 & 0.62 \\
\hline & MAX & 0.77 & 0.29 & 1.53 \\
\hline & IMAX & 0.98 & 2.67 & 4.69 \\
\hline \multirow{3}{*}{2 (KDOJ) } & VRS & 0.61 & 0.35 & 1.00 \\
\hline & MAX & 0.36 & 0.79 & 1.83 \\
\hline & IMAX & 14.99 & 9.09 & 23.77 \\
\hline \multirow{3}{*}{3 (KRP) } & VRS & 0.86 & 0.38 & 1.17 \\
\hline & MAX & 1.59 & 2.68 & 2.85 \\
\hline & IMAX & 0.61 & 3.03 & 3.81 \\
\hline
\end{tabular}


Table 5. RMSE of NRTK techniques

\begin{tabular}{|c|c|c|c|c|}
\hline Points & NRTK & Latitude (cm) & Longitude (cm) & h (cm) \\
\hline \multirow{3}{*}{1 (HELI) } & VRS & 1.23 & 0.20 & 4.65 \\
\hline & MAX & 1.68 & 0.17 & 3.68 \\
\hline & IMAX & 1.43 & 0.82 & 6.20 \\
\hline \multirow{3}{*}{2 (KDOJ) } & VRS & 1.87 & 0.34 & 2.86 \\
\hline & MAX & 1.48 & 0.62 & 4.78 \\
\hline & IMAX & 3.61 & 3.44 & 4.17 \\
\hline \multirow{3}{*}{3 (KRP) } & VRS & 0.80 & 0.47 & 5.24 \\
\hline & MAX & 0.16 & 1.33 & 5.97 \\
\hline & IMAX & 1.80 & 1.09 & 4.43 \\
\hline
\end{tabular}

Table 6. Magnitude and direction of Point 1 (HELI)

\begin{tabular}{|c|c|c|c|c|}
\hline \multirow{2}{*}{ NRTK } & \multicolumn{2}{|c|}{ Magnitude (m) } & \multirow{2}{*}{ Direction } & \multirow{2}{*}{ Remarks } \\
\hline & Horizontal & Vertical & & \\
\hline VRS & 0.0279 & -0.1040 & $350^{\circ} 56^{\prime} 31.56^{\prime \prime}$ & North-West \\
\hline MAX & 0.0378 & -0.0822 & $354^{\circ} 13^{\prime} 44.76^{\prime \prime}$ & North-West \\
\hline IMAX & 0.0369 & -0.1386 & $29^{\circ} 53^{\prime} 56.04^{\prime \prime}$ & North-East \\
\hline
\end{tabular}

Table 7. Magnitude and direction of Point 2 (KDOJ)

\begin{tabular}{|c|c|c|c|c|}
\hline \multirow{2}{*}{ NRTK } & \multicolumn{2}{|c|}{ Magnitude (m) } & \multirow{2}{*}{ Direction } & \multirow{2}{*}{ Remarks } \\
\hline & Horizontal & Vertical & & \\
\hline VRS & 0.0425 & -0.0640 & $169^{\circ} 41^{\prime} 42.72^{\prime \prime}$ & South-East \\
\hline MAX & 0.0360 & -0.1068 & $157^{\circ} 25^{\prime} 45.12^{\prime \prime}$ & South-East \\
\hline IMAX & 0.1116 & 0.0932 & $223^{\circ} 37^{\prime} 13.80^{\prime \prime}$ & South-West \\
\hline
\end{tabular}

Table 8. Magnitude and direction of Point 3 (KRP)

\begin{tabular}{|c|c|c|c|c|}
\hline \multirow{2}{*}{ NRTK } & \multicolumn{2}{|c|}{ Magnitude (m) } & \multirow{2}{*}{ Direction } & \multirow{2}{*}{ Remarks } \\
\hline & Horizontal & Vertical & & \\
\hline VRS & 0.0207 & -0.1172 & $30^{\circ} 46^{\prime} 26.40^{\prime \prime}$ & North-East \\
\hline MAX & 0.0300 & -0.1336 & $83^{\circ} 06^{\prime} 42.12^{\prime \prime}$ & North-East \\
\hline IMAX & 0.0470 & -0.0990 & $148^{\circ} 44^{\prime} 37 \cdot 32^{\prime \prime}$ & South-East \\
\hline
\end{tabular}

As shown in Table 5, the RMSE for all observed points using three (3) dissimilar techniques varies from 0.16 to 3.61 cm for northing, 0.17 to $3.44 \mathrm{~cm}$ for easting and 2.86 to 6.20 cm for height. The RMSE for the height component is the biggest compared to other components. Based on the study conducted by Berber et al. (2012), the vertical accuracy of GNSS is in the order of 2 to 3 times worse than the horizontal component (northing and easting) due to the reason that satellite configuration is better for horizontal determination, which were also proven by Zulkifli et al. (2019) and Ramachandran et al. (2019) in their studies.
Additionally, from Table 4, IMAX at Point 2 has the largest standard deviation with the values of $14.99 \mathrm{~cm}$ for northing, $9.09 \mathrm{~cm}$ for easting and $23.77 \mathrm{~cm}$ for ellipsoidal height. It is considered the worst compared to others that only range between 0.36 to $4.69 \mathrm{~cm}$ for all components. This could be due to the wrong interpretation of the RTCM messages by the receiver. The IMAX technique was originally introduced to support the older receivers that cannot interpret the RTCM 3.1 network messages (Janssen, 2009). However, it should be noted that during the observation, RTCM 3.1 network messages format was used, which most likely to induce the inconsistent result as seen in Table 4. RTCM 
format 3.1 was chosen in order to synchronise the network messages used for all the three (3) NRTK techniques. Since RTCM 3.1 was developed to be more efficient compared to the older versions supported by IMAX technique, there would be some conflicts when the versions were mixed up (different messages types have different compatibility), which might affect the final positioning solution (Brown et. al., 2005; Janssen, 2009; SmartNet North America, 2021).

For northing and easting components, the standard deviation is generally in the order of millimetres level except for IMAX at Point 2 and MAX at Point 3 which are in the range of 1.59 to $14.99 \mathrm{~cm}$. As expected, the standard deviation for the vertical component are much worse than horizontal and typically range from 0.62 to $23.77 \mathrm{~cm}$.

Overall, the magnitude of all the three (3) techniques deviate between 2.07 to $11.16 \mathrm{~cm}$ and 6.40 to $13.86 \mathrm{~cm}$ for horizontal and vertical component, respectively. Meanwhile, for the direction of points, specifically Point 3 , VRS and MAX have the same direction towards the known value (north-east) meanwhile, IMAX shows the direction towards south-east.

Generally, if the accuracy of IMAX technique is excluded into consideration, the values of RMSE for both components (horizontal and vertical) remain within the allowable values, which are $2 \mathrm{~cm}$ for horizontal and $6 \mathrm{~cm}$ for vertical. $2 \mathrm{~cm}$ accuracy is the allowable horizontal tolerance for most of the precise applications such as property boundary analysis, engineering works and change detection, whereas, for vertical tolerance, the information from the GPS measurement is determined maximum three (3) times worse than the horizontal, with the value of $6 \mathrm{~cm}$ (Berber et. al., 2012; Amirrudin et al., 2021). Jamil et al. (2010) have also stated in their study of MyRTKnet in 2010 and beyond, that the accuracy in the horizontal and height component were 1 $\mathrm{cm}$ and between 5 to $7 \mathrm{~cm}$, respectively for areas within 30 $\mathrm{km}$ from the network using VRS technique. In terms of standard deviation obtained from the repetition of measurements, by excluding the NRTK of IMAX technique, there are changes within the maximum values of $2.68 \mathrm{~cm}$ for horizontal and $2.85 \mathrm{~cm}$ for vertical components and this output aligns with the research conducted by Baybura et al. (2019), showing almost similar values which are $\pm 1.5(\mathrm{~N}$ and $\mathrm{E}$ measurement) and $\pm 4 \mathrm{~cm}$ (up).

\section{B. Comparison of Plane Coordinates with Known Values (Mapping)}

In this part, comparisons between the known CRM coordinates and the coordinates from NRTK techniques were assessed at each CRM point in Cassini Soldner geocentric representing the plane coordinates. The values of standard deviation are tabulated in Table 9. Then, the result from those comparisons was used to calculate the RMSE in northing, easting and ellipsoidal height, as shown in Table 10. The magnitude and direction of output from each NRTK techniques are presented as well in Tables 11 to 13.

Table 9. Mean coordinates and standard deviation of NRTK techniques

\begin{tabular}{ccccc}
\hline \multirow{2}{*}{ Points } & NRTK & \multicolumn{3}{c}{ Mean Coordinates } \\
\cline { 3 - 5 } CRM (J12892) & VRS & -58600.7408 & 21364.8018 & 28.8862 \\
& MAX & -58600.7544 & 21364.7828 & 28.8970 \\
& IMAX & -58600.7694 & 21364.8424 & 28.7812 \\
CRM (J12893) & VRS & -58620.4120 & 21465.8742 & 33.7442 \\
& MAX & -58620.4068 & 21465.8640 & 33.7542 \\
CRM (J12894) & IMAX & -58620.4198 & 21465.8552 & 33.8684 \\
Points & VRS & -58571.4970 & 21589.8530 & 30.8730 \\
CRM (J12892) & MAX & -58571.4982 & 21589.8820 & 30.8664 \\
& IMAX & -58571.4964 & 21589.8516 & 30.8484 \\
NRTK & VRS & N (cm) & E (cm) & h (cm) \\
\hline
\end{tabular}




\begin{tabular}{ccccc}
\hline & MAX & 0.42 & 0.33 & 0.54 \\
& IMAX & 3.72 & 7.46 & 11.80 \\
VRM (J12893) & MAX & 0.32 & 0.29 & 1.33 \\
& IMAX & 0.18 & 0.51 & 1.44 \\
& VRS & 0.37 & 0.43 & 2.24 \\
CRM (J12894) & MAX & 0.43 & 0.10 & 1.26 \\
& IMAX & 0.19 & 0.47 & 0.34 \\
& & 0.15 & 0.61 & 1.03 \\
\hline
\end{tabular}

Table 10. RMSE of NRTK techniques

\begin{tabular}{ccccc}
\hline Points & NRTK & N (cm) & E (cm) & h (cm) \\
\hline \multirow{2}{*}{ CRM (J12892) } & VRS & 0.30 & 2.41 & 3.57 \\
& MAX & 0.91 & 1.56 & 3.09 \\
CRM (J12893) & IMAX & 1.58 & 4.22 & 8.26 \\
& VRS & 1.79 & 3.14 & 2.85 \\
& MAX & 1.56 & 2.68 & 2.41 \\
CRM (J12894) & IMAX & 2.14 & 2.29 & 2.70 \\
& VRS & 1.03 & 0.76 & 2.10 \\
& MAX & 1.08 & 2.06 & 2.40 \\
\hline
\end{tabular}

Table 11. Magnitude and direction of CRM J12892

\begin{tabular}{|c|c|c|c|c|}
\hline \multirow{2}{*}{ NRTK } & \multicolumn{2}{|c|}{ Magnitude (m) } & \multirow{2}{*}{ Direction } & \multirow{2}{*}{ Remarks } \\
\hline & Horizontal & Vertical & & \\
\hline VRS & 0.0542 & -0.0798 & $277^{\circ} 12^{\prime} 12.96^{\prime \prime}$ & North-West \\
\hline MAX & 0.0403 & -0.0690 & $300^{\circ} 22^{\prime} 44.76^{\prime \prime}$ & North-West \\
\hline IMAX & 0.1008 & -0.1848 & $290^{\circ} 33^{\prime} 21.60^{\prime \prime}$ & North-West \\
\hline
\end{tabular}

Table 12. Magnitude and direction of CRM J12893

\begin{tabular}{|c|c|c|c|c|}
\hline \multirow{2}{*}{ NRTK } & \multicolumn{2}{|c|}{ Magnitude (m) } & \multirow{2}{*}{ Direction } & \multirow{2}{*}{ Remarks } \\
\hline & Horizontal & Vertical & & \\
\hline VRS & 0.0808 & -0.0638 & $299^{\circ} 40^{\prime} 28.20^{\prime \prime}$ & North-West \\
\hline MAX & 0.0694 & -0.0538 & $300^{\circ} 06^{\prime} 49.32^{\prime \prime}$ & North-West \\
\hline IMAX & 0.0700 & -0.0604 & $310^{\circ}$ o1' $58.80^{\prime \prime}$ & North-West \\
\hline
\end{tabular}

Table 13. Magnitude and direction of CRM J12894

\begin{tabular}{ccccc}
\hline \multirow{2}{*}{ NRTK } & \multicolumn{2}{c}{ Magnitude (m) } & \multirow{2}{*}{ Direction } & \multirow{2}{*}{ Remarks } \\
\cline { 2 - 3 } & Horizontal & Vertical & & \\
\hline VRS & 0.0286 & -0.0470 & $323^{\circ} 31^{\prime} 50.88^{\prime \prime}$ & North-West \\
MAX & 0.0520 & -0.0536 & $297^{\circ} 44^{\prime} 53.88^{\prime \prime}$ & North-West \\
IMAX & 0.0273 & -0.0716 & $325^{\circ} 08^{\prime} 43.80^{\prime \prime}$ & North-West \\
\hline
\end{tabular}


As shown in Table 10, the RMSE for all the observed points using the three (3) different techniques range from 0.30 to $2.14 \mathrm{~cm}$ for northing, 0.70 to $4.22 \mathrm{~cm}$ for easting and 2.10 to $8.26 \mathrm{~cm}$ for ellipsoidal height. The result for the height component is the biggest of all. As previously mentioned, error in vertical component is always significantly worse than the horizontal.

However, IMAX at CRM J12892 has the largest standard deviation, which is $3.72,7.46$ and $11.80 \mathrm{~cm}$ for northing, easting and height, respectively (refer Table 9). It is considered the worst compared to other techniques that only range between 0.18 to $1.44 \mathrm{~cm}$ for all components. The values show better precision compared to the standard deviation values computed by Baybura et al. (2019) which were \pm 1.5 and $\pm 4 \mathrm{~cm}$ for horizontal and vertical component, respectively.

In addition, the magnitude of all techniques generally range from 2.73 to $10.08 \mathrm{~cm}$ for horizontal and 4.70 to 18.48 $\mathrm{cm}$ for vertical (refer Tables 11 to 13 ). Meanwhile, for the direction, VRS, MAX and IMAX project the same direction towards the known values.

Interestingly, the magnitude is bigger compared to the acceptable value, which is $2 \mathrm{~cm}$ for horizontal position and 6 cm for vertical position, specifically for cadastral works (Jabatan Ukur dan Pemetaan Malaysia, 2009). However, since the comparison was made between NRTK and static techniques, the accuracy of NRTK technique would contribute to error in the solution with the magnitude differences up to $5 \mathrm{~cm}$ for horizontal and $7 \mathrm{~cm}$ for vertical components due to short period of data in modelling distance-dependent errors (Baybura et al., 2019). Besides, it should also be noted that the observation took place in an urban area, thus there could be errors from the multipath (Deep et al., 2018) and interference from the elevation mask as well.

\section{Baseline Lengths}

This section discusses the accuracy and precision of NRTK techniques in terms of baseline lengths between the rover and the nearest MyRTKnet station (JHJY). The distance of 5 km between JHJY and J12894 represents the short baseline length, whereas the Point 2 (KDOJ) symbolises the long baseline length with the distance of $20 \mathrm{~km}$ from JHJY station. All results are tabulated and plotted in Table 14 and Figure 9.

Table 14. Standard deviation of Point 2 and J12894

\begin{tabular}{|c|c|c|c|c|}
\hline Points & NRTK & Latitude/N (cm) & Longitude/E (cm) & h (cm) \\
\hline \multirow{3}{*}{2 (KDOJ) } & VRS & 0.61 & 0.35 & 1.00 \\
\hline & MAX & 0.36 & 0.79 & 1.83 \\
\hline & IMAX & 14.99 & 9.09 & $23 \cdot 77$ \\
\hline \multirow{3}{*}{$\begin{array}{c}\text { CRM } \\
\text { (J12894) }\end{array}$} & VRS & 0.43 & 0.10 & 1.26 \\
\hline & MAX & 0.19 & 0.47 & 0.34 \\
\hline & IMAX & 0.15 & 0.61 & 1.03 \\
\hline
\end{tabular}



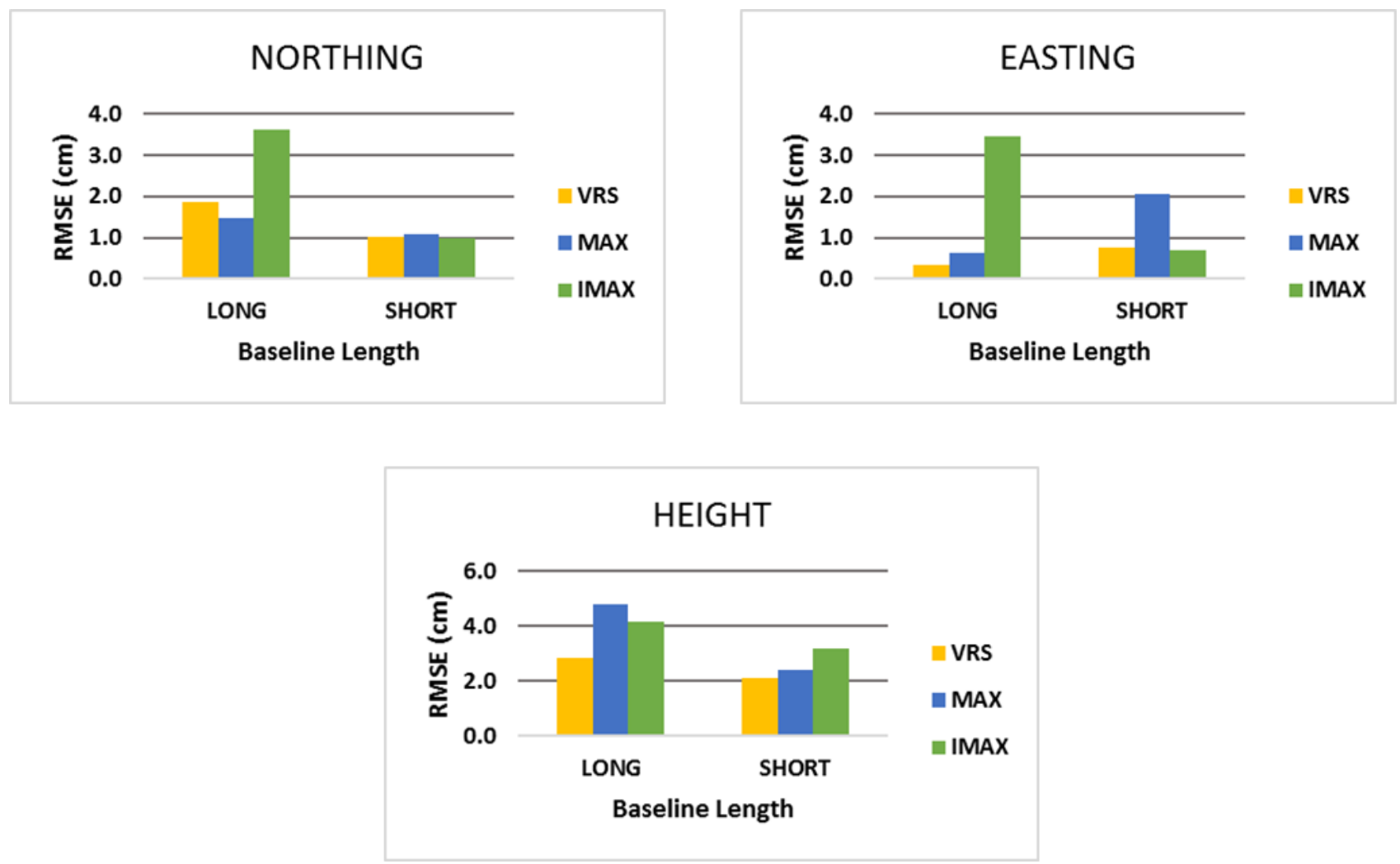

Figure 9. RMSE of northing, easting and height components

Based on Table 14, the baseline length between the rover and the nearest MyRTKnet station does affect the horizontal and vertical components. From the comparison, it shows that the long baseline has the highest RMSE value for all components compared to the short baseline. This might probably happen due to the effect of distance-dependent errors (Musa, 2007). Apart from that, if there are high ionospheric and tropospheric activities, the $15 \mathrm{~km}$ distance might become less than $10 \mathrm{~km}$ because dispersive and nondispersive errors swiftly changed from the base station to the rover side (Hu et al., 2002). Furthermore, referring to Baybura et al. (2019), they observed the differences between NRTK-static and in east coordinates were at a maximum of $2 \mathrm{~cm}$ based on $5 \mathrm{~km}$ baseline and this value was estimated to be increased when moving away from reference station. In terms of RMSE (refer Figure 9) for northing and easting components of long baseline, IMAX at Point 2 has the greatest values compared to others, which are 3.61 and 3.44 $\mathrm{cm}$, respectively. Nevertheless, MAX has the lowest value of northing which is at $1.48 \mathrm{~cm}$ and VRS has the lowest values for easting and height, which are $0.34 \mathrm{~cm}$ and $2.86 \mathrm{~cm}$, respectively.
For vertical component, the standard deviation is generally in the order of centimetres level except for MAX at CRM (J12894), which is $3.4 \mathrm{~mm}$. For northing and easting, the standard deviations are at millimetres level except for IMAX of Point 2, which are 14.99 and $9.09 \mathrm{~cm}$, respectively. Overall, from Table 14 and Figure 9, IMAX gives the biggest values for both standard deviation and RMSE. As stated before, this is due to the misinterpretation of RTCM messages related to GNSS equipment.

\section{CONCLUSION}

In this study, the accuracy of the NRTK techniques based on VRS, MAX and IMAX approaches was successfully assessed for geodetic (positioning) and plane coordinates (mapping) in Malaysia. Due to different functions, concepts and techniques of each NRTK approach, the outcomes generated were also varied. Therefore, the significance of NRTK approaches can be seen from the comparison of their accuracies which could be beneficial to MyRTKnet users in identifying the best technique that can provide the best solution with the smallest error value in terms of geodetic and plane coordinates. 
Among the three (3) techniques tested in this study, there were no noticeable differences between them except for IMAX, showing significant differences at some points. In general, the accuracy of horizontal and vertical components for both geodetic and plane coordinates were in cm level for each technique. For geodetic coordinates, the RMSE values representing accuracy ranged from 0.16 to $3.61 \mathrm{~cm}$ and 2.86 to $6.20 \mathrm{~cm}$ for horizontal and vertical component, respectively. Meanwhile, for plane coordinates, the RMSE values varied from 0.3 to $4.22 \mathrm{~cm}$ for horizontal and 2.1 to $8.26 \mathrm{~cm}$ for vertical components. Prior to the discussion in the previous section, the allowable accuracy values for horizontal and vertical components were $2 \mathrm{~cm}$ and $6 \mathrm{~cm}$, respectively. However, if the IMAX technique is treated as an exception due to the misinterpretation of RTCM network messages, the RMSE values for geodetic and plane coordinates are both within the allowable tolerance as the biggest values for all components were derived from IMAX technique.

Furthermore, in terms of baseline length, the distance between the rover and the closest CORS station affected the horizontal and vertical accuracy as well as precision. As the rover moved farther away from JHJY station, the accuracy and precision were also deteriorated due to the errors in GNSS measurement such as ionospheric, tropospheric, signal obstruction and multipath as well as the factor of geometric configuration of satellites.

Finally, it may be concluded that any of the two NRTK techniques of VRS and MAX can be safely selected for positioning (geodetic coordinates) and mapping (plane coordinates) purposes as there was not much differences between those two techniques with regard to accuracy and precision. Nevertheless, this is not the case for IMAX since the RTCM format needs to be compatible with GNSS equipment and technique applied. For example, RTCM 3.1 network messages for MAX technique and RTCM below 3.1 network messages (older type receivers) for IMAX technique. As this study was conducted based on short observation period, further studies involving longer observation time to acquire data redundancy and increase data precision are recommended. It is also suggested to carry out observations in the same survey conditions to avoid any biases in the solutions (ionospheric and tropospheric effect, satellite geometry etc.) for all geodetic and plane coordinates points. The baseline length for specific applications that require high accuracy and precision of data should be considered as well.

\section{ACKNOWLEDGEMENT}

The authors would like to thank the staff of Geodesy and Astronomy Laboratory (FABU) for providing the equipment and helping in the course of data collection and processing at UTM and Kg. Melayu, Johor Bahru, Johor. We fully acknowledge the Department of Survey and Mapping Malaysia (DSMM) for providing the MyRTKnet data. This project is funded by the Ministry of Higher Education (MOHE) Malaysia and Universiti Teknologi Malaysia under the Research University Grant (RUG) Tier 2, Vote Number: Q.J130000.2652.16J88.

\section{REFERENCES}

Amiruddin, MA, Din, AHM, Zulkifli, NA, Amat, MAC \& Hamden, MH 2021, 'Assessment of the accuracy and precision of MyRTKnet real-time services', Jurnal Teknologi, vol. 83, no. 1, pp. 93-103.

Bae, TS \& Kim, M 2018, 'Performance analysis of networkRTK techniques for drone navigation considering ionospheric conditions', Journal of Sensors, vol. 2018, pp. 1-8.
Baybura, T, Tiryakioglu, I, Ugur, MA, Solak, HI \& Safak, S 2019, 'Examining the accuracy of network RTK and long base RTK methods with repetitive measurement', Journal of Sensors, vol. 2019, pp. 1-12.

Berber, M, \& Arslan, N 2013, 'Network RTK: A case study in Florida', Measurement, vol. 46, no. 8, pp. 2798-2806.

Berber, M, Ustun, A \& Yetkin, M 2012, 'Comparison of accuracy of GPS techniques', Measurement, vol. 45, no. 7, pp. $1745^{-1746 . ~}$ 
Brown, N, Keenan, R, Richter, B \& Troyer, L 2005, 'Advances in ambiguity resolution for RTK applications using the new RTCM V3.0 master-auxiliary messages', in ION GPS 2005: Proceedings of the $18^{\text {th }}$ International Technical Meeting of the Satellite Division of the Institute of Navigation, Long Beach, 13-16 September 2005, Long Beach Convention Center, Long Beach.

Canadian Council on Geomatics, 2020, RTK and NRTK, viewed 19 March 2021, <http://cgrsc.ca/resources/gnssaugmentation/rtk-and-nrtk/>.

Chan, KK \& Ben, LCH 2007, 'The Hong Kong satellite positioning reference station network (SatRef) - system configuration, applications and services', in Proceedings of FIG Working Week 2007, Hong Kong, 13-17 May 2007, Kowloon Shangri-La, Hong Kong.

Cina, A, Dabove, P, Manzino, AM \& Piras, M 2015, 'Network real time kinematic (NRTK) positioning - description, architecture and perfomances', eds S Jin, in Satellite positioning - methods, models and applications, IntechOpen, London, pp. 23-45.

Deep, S, Raghavendra, S \& Bharath, BD 2018, 'GPS SNR prediction in urban environment', The Egyptian Journal of Remote Sensing and Space Science, vol. 21, no. 1, pp. 8385.

Euler, HJ, Keenan, CR, Zebhauser, BE \& Wübbena, G 2001, 'Study of a simplified approach in utilizing information from permanent reference station arrays', in ION GPS 2001: Proceedings of the $14^{\text {th }}$ International Technical Meeting of the Satellite Division of the Institute of Navigation, Salt Lake City, 11-14 September 2001, Salt Palace Convention Center, Salt Lake City.

Garrido, MS, Giménez, E, Lacy, MCD \& Gil, AJ 2011, 'Testing precise positioning using RTK and NRTK corrections provided by MAC and VRS approaches in SE Spain', Journal of Spatial Science, vol. 56, no. 2, pp. 169184.

Ghilani CD (eds) 2010, Adjustment computations: spatial data analysis, $5^{\text {th }}$ edn, Wiley, New Jersey, United States.

Gumus, K \& Selbesoglu, MO 2019, 'Evaluation of NRTK GNSS positioning menthods for displacement detection by a newly designed displacement monitoring system', Measurement, vol. 142, pp. 131-137.

Hassan, MI, Ahmad-Nasruddin, MH, Yaakop, IA \& AbdulRahman, A 2008, 'An integrated 3D cadastre-Malaysia as an example', The International Archives of the
Photogrammetry, Remote Sensing and Spatial Information Sciences, vol. 37, no. B4, pp. 121-26.

Howel, DC (eds) 1998, Statistical methods for psychology, 7 edn, Cengage Wadsworth, Belmont, Canada.

Hu, GR, Khoo, VHS, Goh, PC \& Law, CL 2002, 'Internetbased GPS VRS RTK positioning with a multiple reference station network', Journal of Global Positioning Systems, vol. 1, no. 2, pp. 113-120.

Inal, C, Bulbul, S \& Bilgen, B 2018, 'Statistical analysis of accuracy and precision of GNSS receivers used in network RTK', Arabian Journal of Geosciences, vol. 11, no. 227, pp. $1-8$.

Jabatan Ukur dan Pemetaan Malaysia, 2009, Garis panduan amalan kerja ukur kadaster dalam persekitana eKadaster, Pekeliling Ketua Pengarah Ukur dan Pemetaan bilangan 6 tahun 2009, Kuala Lumpur.

Jamil, H, Mohamed, A \& Chang D 2010, 'The Malaysia RealTime Kinematic GNSS Network (MyRTKnet) in 2010 and beyond', in FIG Congress 2010, 11-16 April 2010, Sydney, Australia.

Janssen, V 2009, 'A comparison of the VRS and MAC principles for network RTK', in International Global Navigation Satellite Systems Society Symposium 2009, Queensland, 1-3 December 2009, Holiday Inn Surfers Paradise, Queensland.

Jensen, ABO 2017, High accuracy GNSS positioning, KTH Space Center, viewed 3 June 2020, <https://gidec.abe.kth.se/GEOWEB/docs_mostar/jensen. pdf $>$.

Kim, MH \& Bae, TS 2015, 'Preliminary analysis of networkRTK for navigation', Journal of the Korean Society of Surveying, geodesy, Photogrammetry and Cartography, vol. 33, no. 5, pp. 343-351.

Landau, H, Vollath, U \& Chen, X 2002, 'Virtual reference station systems', Journal of Global Positioning Systems, vol. 1, no. 2, pp. 137-143.

Lim, S, Musa, TA \& Rizos, C 2020, Modelling of dispersive and non-dispersive effects on network-based real-time kinematic positioning, viewed 3 June 2020, $<$ https://citeseerx.ist.psu.edu/viewdoc/download?doi=10. 1.1.588.729\&rep $=$ rep1\&type $=p d f>$.

Musa, T A 2007, 'Analysis of residual atmospheric delay in the low latitude regions using network-based GPS positioning', PhD thesis, University of New South Wales, Sydney, New South Wales. 
Ogutcu, S \& Kalayci, I 2017, 'Investigating Precision of Network Based RTK Techniques: Baseline Length Is Concerned', World Journal of Research and Review, vol. 5, no. 1 , pp. 1-3.

Ogutcu, S, \& Kalayci, I 2016, 'Investigation of network-based RTK techniques: a case study in urban area', Arabian Journal of Geosciences, vol. 9, no. 99, pp. 1-12.

Park, B 2008, 'A study on reducing temporal and spatial decorrelation effect in GNSS augmentation system', PhD thesis, Seoul National University, Seoul, Korea.

Ramachandran, D, Din, AHM, Omar, AH \& Ibrahim, SA 2019, 'Real-Time Precise Point Positioning (RT-PPP) for positioning and mapping', eds B Pradhan, in Lecture Notes in Civil Engineering, Springer, Singapore, pp. 891-913.

Shariff, NSM, Musa, TA, Ses, S, Omar, K, Rizos, C \& Lim, S 2009, 'ISKANDARnet: a network-based real-time kinematic positioning system in ISKANDAR Malaysia for research platform' in $10^{\text {th }}$ South East Asian Survey Congress 2009, Bali, 4-7 August 2009, Bali International Convention Center, Bali.

SmartNet North America 2021, What are the different correction formats \& mountpoints that you offer?, viewed 19 March 2021, <https://support.smartnetna.com/hc/enus/articles/360000869388-What-are-the-differentcorrection-formats-Mountpoints-that-you-offer->.

Soko, M 2018, 'Validity and reliability of free GPS postprocessing services for the southern region of Peninsular Malaysia', Master thesis, Universiti Teknologi Malaysia, Johor Bahru, Johor.

Takac, F \& Zelzer, O 2008, 'The relationship between network RTK solutions MAC, VRS, PRS, FKP and i-MAX', in ION GNSS 2008: Proceedings of the 21st International Technical Meeting of the Satellite Division of The Institute of Navigation, Savannah, 16-19 September 2008, Savannah International Convention Center, Savannah.

Wanninger, L 2008, Introduction to network RTK, viewed 19 March

http://www.wasoft.de/e/iagwg451/intro/introduction.ht $\underline{\mathrm{ml}}>$.

Wubbena, G, Bagge, A \& Schmitz, M 2001, 'Network-based techniques for RTK applications', in GPS Symposium, 1416 November 2001, Tokyo, Japan.

Zulkifli, NA, Din, AHM \& Omar, AH 2019, 'The impact of different International Terrestrial Reference Frames (ITRFs) on positioning and mapping in Malaysia', eds B
Pradhan, in Lecture Notes in Civil Engineering, Springer, Singapore, pp. 671-690. 